Jurnal Media Agribisnis Vol. 2 No. 2 Tahun 2017 Hal 60 - 68

Media Komunikasi Hasil Penelitian Bidang Ilmu Agribisnis

ISSN print 2548-7027

ISSN online 2541-6898

\title{
KAJIAN PERSEPSI DAN SIKAP MASYARAKAT TANI DALAM PROGRAM GERTAK TANPA DUSTA DI KABUPATEN TANJUNG JABUNG TIMUR, PROVINSI JAMBI
}

\author{
Nida Kemala ${ }^{1 *}$, dan Mulyani ${ }^{2 *}$ \\ ${ }^{1}$ Program Studi Agribisnis, Fakultas Pertanian Universitas Batanghari \\ ${ }^{2}$ Program Studi Agribisnis, Fakultas Pertanian Universitas Batanghari \\ Jl. Slamet Riyadi-Broni, Jambi. 36122. Telp. +6274160103 \\ *email korespondesi : nidakemala@yahoo.com
}

\begin{abstract}
This study was conducted in "Tanjung Jabung Timur" Regency, Jambi Province where programs of "Gerakan Serentak Tanam Padi Dua kali Setahun (Gertak Tanpa Dusta)" was applied. The research focused on a farmer perception toward to the program, their attitude of independently paddy farming and the relationship between both their perception and their attitude. Total population were 485 so the number of sample was 73 farmers (15\%), and was taken by proportional random sampling methode. While the method of analysis to find out the relation between both variables was done by non parametric statistical tests namely Chi-Square $2 \times 2$. The prospect of this research was to give the government in making a choise of the program sustainability.The result showed that most of farmers had $80,8 \%$ showed good perception toward to the program and it's only 14 farmers $(19,2 \%)$ showed bad. Their attitude of independently paddy farming showed $63 \%$ low and only $37 \%$ farmers had high category. Majority of respondents who have the good pereption showed low attitude of independently paddy farming. There were 59 farmers with good perception and it showed 69,5\% had low attitude. In contrary the majority of bad perception farmers showed high attitude as $64,3 \%$. There were a significantly relation between the farmer perception toward to the program and their attitude of independently paddy farming in "Gertak Tanpa Dusta" program.
\end{abstract}

Keywords: Program, Perception, Attitude, Farmer

\begin{abstract}
Abstrak
Penelitian ini dilakukan di Kabupaten Tanjung Jabung Timur, Provinsi Jambi dimana di lokasi inilah program Gerakan Serentak Tanam Padi Dua Kali Setahun (Gertak Tanpa Dusta) dilakukan. Penelitian ini difokuskan pada kajian persepsi petani terhadap program, sikap kemandirian mereka dalam berusahatani padi dan hubungan antara persepsi dengan sikap kemandirian. Jumlah populasi sebanyak 485 petani maka jumlah sampel sebanyak 73 petani (15\%), yang ditentukan dengan metode "proporsional random sampling". Sedangkan metode analisis untuk melihat hubungan antara kedua variabel tersebut dilakukan oleh non-parametrik yaitu uji chi-square $2 \times 2$. Prospek penelitian ini adalah untuk memberikan pilihan bagi pemerintah dalam menentukan keberlangsungan suatu program. Hasil penelitian menunjukkan bahwa mayoritas petani $(80,8 \%)$ memiliki persepsi yang baik terhadap program dan hanya 14 petani $(19,2 \%)$ menunjukkan persepsi kurang baik. Sikap kemandirian dalam budidaya padi menunjukkan $63 \%$ rendah dan hanya $37 \%$ petani yang memiliki sikap kemandirian tinggi. Kebanyakan responden yang memiliki persepsi baik terhadap program menunjukkan sikap kemandirian dalam berusahatani padi yang rendah. Dari 59 petani
\end{abstract}


Jurnal Media Agribisnis Vol. 2 No. 2 Tahun 2017 Hal 60 - 68

Media Komunikasi Hasil Penelitian Bidang Ilmu Agribisnis

ISSN print 2548-7027

ISSN online 2541-6898

dengan persepsi baik terdapat 69,5\% diantaranya yang memiliki sikap kemandirian rendah. Sebaliknya sebagian besar persepsi kurang baik menunjukkan sikap kemandirian yang tinggi yaitu $64,3 \%$. Terdapat hubungan yang signifikan antara persepsi petani terhadap program dan sikap kemandirian dalam program Gertak Tanpa Dusta.

Kata kunci: Program, Persepsi, Sikap, Petani

\section{PENDAHULUAN}

BPS Provinsi Jambi (2017) menggambarkan ekonomi Provinsi Jambi tahun 2016 tumbuh 4,37\%, terlihat mengalami kenaikan dari tahun 2015 sebesar 4,20\%. Tanjung Jabung Timur (Tanjabtim) merupakan salah satu kabupaten di Provinsi Jambi yang berpotensi di sektor pertanian. Total PDRB kabupaten tersebut tahun 2015 mengalami penurunan menjadi $\mathrm{Rp}$. 17.786,30 milyar atas dasar harga berlaku, namun ada kecenderungan meningkat pada 5 tahun terakhir. (BPS Kabupaten Tanjabtim, 2016). Tanjabtim juga memiliki potensi sebagai wilayah penghasil tanaman pangan dengan lahan sawah terluas yaitu $31.939 \mathrm{Ha}$ sebagai peringkat ke-dua setelah Kabupaten Kerinci (28133 Ha) pada tahun 2014. Luas panen padi menurun dimana pada tahun 2015 menjadi 18.322 Ha dengan total produksi padi sebesar 75.109 ton, sehingga produktivitasnya adalah 4,09 ton/Ha. Penurunan produksi pada periode 20112012 disebabkan karena menurunnya luas tanam, namun terjadi kenaikan produktivitas pada tahun 2013 sampai 2015.

Sebelum tahun 2011, lahan sawah hanya ditanam satu kali setahun dan setelahnya lahan dibiarkan bera secara alami. Mulai tahun 2011, dicanangkan program penanaman dua kali setahun (IP200) dengan slogan Gerakan Tanam Padi Dua Kali Setahun (Gertak tanpa dusta). Kecenderungan meningkatnya PDRB pada 5 tahun terakhir ini berkaitan dengan adanya pelaksanaan program yang sudah dilaksanakan sejak 2011. Program ini digagas oleh pejabat tingginya, sebagai suatu program yang dijadikan sebagai pemicu pembangunan pertanian perdesaan. Dalam pelaksanaannya proram ini diharapkan selain untuk mengantisipasi adanya fenomena alih fungsi lahan juga diharapkan mampu meningkatkan pendapatan daerah serta untuk dapat benar-benar menyentuh harapan masyarakat yang tentu saja berkaitan dengan kesejahteraan. Hal ini ditandai dengan meningkatnya pendapatan di sektor pertanian. Dengan demikian gairah ekonomi pasar akan bangkit kembali dimana banyak petani yang mampu memenuhi kebutuhan baik primer maupun sekunder, hal ini merupakan dambaan bagi masyarakat petani.

Berdasarkan uraian tersebut, perlu adanya kajian permasalahan yang berkaitan dengan gambaran persepsi petani terhadap program Gertak Tanpa Dusta, gambaran sikap kemandirian petani dalam usahatani padi dan kaitan antara persepsi petani terhadap program Gertak Tanpa Dusta dengan sikap kemandirian petani dalam usahatani padi di Kabupaten Tanjabtim, Provinsi Jambi.

\section{METODOLOGI PENELITIAN}

Kajian ini dilaksanakan di Kabupaten Tanjabtim. Dari sejumlah kecamatan pelaksanakan program Gerakan Serentak Tanam Padi Dua Kali Setahun "Gertak Tanpa Dusta" ditetapkan dengan sengaja dua kecamatan dengan pertimbangan bahwa kecamatan dengan luas wilayah di atas rata-rata. Berdasarkan ketentuan di atas maka peneliti menetapkan 2 kecamatan pelaksanakan program tersebut yaitu Kecamatan 
Jurnal Media Agribisnis Vol. 2 No. 2 Tahun 2017 Hal 60 - 68

Media Komunikasi Hasil Penelitian Bidang Ilmu Agribisnis

ISSN print 2548-7027

ISSN online 2541-6898

Rantau Rasau dan Kecamatan Nipah Panjang. Objek penelitian terdiri dari petani padi yang telah mengikuti program. Sedangkan ruang lingkup kajian ini dibatasi pada gambaran persepsi masyarakat tani terhadap program dan sikap kemandirian masyarakat tani serta kaitan antara persepsi dan sikap tersebut.

Jenis data berupa data primer dan data sekunder. Data primer diperoleh dikumpulkan melalui survei lapangan dan bersumber langsung dari sampel melalui wawancara menggunakan quisioner yang telah disiapkan. Sedangkan data sekunder bersumber dari instansi terkait dan laporan-laporan hasil kajian yang berhubungan dengan kajian ini. Sebagai sumber data sekunder dalam penelitian ini diperoleh dari literatur-literatur dan instansi-instansi terkait.

Terdapat tiga hal yang harus diperhatikan dalam menentukan besar kecilnya sampel menurut Singarimbun dan Effendi (1998) yaitu derajat keseragaman, ketelitian yang dikehendaki, biaya, waktu dan tenaga kerja yang tersedia. Kemudian menurut Winarno (1994), bila populasi cukup homogen, terhadap populasi di bawah 100 dapat digunakan sampel sebesar 50\%, bila populasi di atas 100 dapat diambil sampel sebesar 15\%, dan juga sampel manusia hendaknya di atas 30 orang besarnya. Jumlah populasi peserta program adalah sebanyak 485 petani. Berdasarkan pertimbangan di atas dimana jumlah populaso di atas 100 maka sampel diambil sebesar $15 \%$ yaitu sebanyak 73 petani. Banyaknya jumlah petani sampel pada masing-masing kecamatan adalah seperti terlihat pada Tabel 1.

Tabel 1. Jumlah Sub-populasi dan Sub-sampel Peserta Gertak Tanpa Dusta di Lokasi Penelitian

\begin{tabular}{cccc}
\hline No. & Nama Kecamatan & $\begin{array}{c}\text { Jumlah Sub-populasi } \\
\text { (orang) }\end{array}$ & $\begin{array}{c}\text { Jumlah Sub-sampel } \\
\text { (orang) }\end{array}$ \\
\hline 1. & Nipah Panjang & 235 & 35 \\
2. & Rantau Rasau & 250 & 38 \\
& Jumlah & 485 & 73 \\
\hline
\end{tabular}

Selanjutnya, khusus untuk pengambilan besarnya sampel pada populasi peserta program yang terdiri dari dua kecamatan, maka digunakan rumus proporsional random sampling (Nazir, 1988) yaitu :

$$
\begin{array}{ll}
n i=\frac{N i}{N} . n & \text { Dimana: } \\
& \mathrm{n}_{\mathrm{i}}=\text { Jumlah total sub sampel petani } \\
& \mathrm{N}_{\mathrm{i}}=\text { Jumlah total sub populasi petani } \\
& \mathrm{N} \quad=\text { Jumlah total populai petani } \\
& \mathrm{n} \quad=\text { Jumlah total sampel petani }
\end{array}
$$

Data yang diperbolehkan dari penelitian ini ditampilkan dengan menggunakan tabulasi kemudian dianalisis secara deskriptif. Untuk mengetahui kaitan antara persepsi masyarakat tani terhadap program dengan sikap kemandirian masyarakat tani untuk sampel besar (> 30) bila untuk tabel 2 X2 ini tidak terdapat nilai frekuensi harapan yang lebih kecil dari 5 (lima) dan tidak satupun frekuansi observasi yang sama dengan nol, maka dianalisis dengan uji statistik non parametik Chi-Square 2x2 (Sugiyono,2004) dengan rumusan sebagai berikut: 
Jurnal Media Agribisnis Vol. 2 No. 2 Tahun 2017 Hal 60 - 68

Media Komunikasi Hasil Penelitian Bidang Ilmu Agribisnis

ISSN print 2548-7027

ISSN online 2541-6898

$$
\begin{aligned}
& \left.\mathrm{X}^{2}=\quad \mathrm{n}(|\mathrm{ad}-\mathrm{bc}|-\mathrm{n} / 2)\right)^{2} \quad \begin{array}{l}
\text { Dimana : } \\
\mathrm{X}^{2}: \text { Chi kuadrat hasil perhitungan }
\end{array} \\
& (a+c)(b+d)(c+d)(a+b) \quad a-d \quad \text { : Frekuensi dari kombinasi dua } \\
& \text { kategorin : Jumlah sampel } \\
& \mathrm{X}^{2} \text { tabel : 3,841 ( } \mathrm{X}^{2} \text { pada } \alpha=0,05 \text { dan } \\
& \mathrm{Db}=(\mathrm{b}-1)(\mathrm{k}-1)
\end{aligned}
$$

Tabel 2. Model Analisis Uji Chi - Square dengan Kontingensi $2 \times 2$

$$
\text { Sikap Kemandirian }
$$

Variable yang diteliti

\begin{tabular}{cccc} 
Kategori Persepsi & Tinggi & Rendah & Jumlah \\
\hline Baik & $\mathrm{a}$ & $\mathrm{b}$ & $(\mathrm{a}+\mathrm{b})$ \\
Kurang baik & $\mathrm{c}$ & $\mathrm{d}$ & $(\mathrm{c}+\mathrm{d})$ \\
Jumlah & $(\mathrm{a}+\mathrm{c})$ & $(\mathrm{b}+\mathrm{d})$ & $\mathrm{n}$ \\
\hline
\end{tabular}

Catatan : Apabila tabel kontingensi $2 \times 2$ seperti di atas, tetapi tidak memenuhi syarat seperti di atas, yaitu ada sel dengan frekuensi harapan kurang dari 5, atau terdapat frekuensi observasi $=0$, maka rumus harus diganti dengan rumus "Fisher Exact Test".

Adapun hipotesis sebagai berikut :

Ho : $\mathrm{X}^{2}=0$

$\mathrm{Ha}: \mathrm{X}^{2} \neq 0$

Dalam pengujian $\mathrm{X}^{2}$ hitung dibanding dengan $\mathrm{X}^{2}$ Tabel dengan $\mathrm{db}=1$ pada tingkat kepercayaan $95 \%$ yaitu 3,85, dengan ketentuan sebagai berikut :

1. Terima $\mathrm{H}_{0}$ jika nilai $\mathrm{X}^{2}$ hitung $\leq \mathrm{X}^{2}$ tabel

2. Tolak $\mathrm{H}_{0}$ jika nilai $\mathrm{X}^{2}$ hitung $>\mathrm{X}^{2}$ tabel

Untuk menyamakan persepsi mengenai variabel-variabel yang diukur dalam kajian ini dengan pengertian dan batasan operasional yang digunakan sebagai berikut:

1. Sampel : Petani padi peserta program Gertak Tanpa Dusta

2. Persepsi adalah pandangan atau penilaian responden terhadap program Gertak Tanpa Dusta. Dalam hal ini persepsi diukur dengan memberikan skor atas penilaian terhadap kegiatan Program Gertak Tanpa Dusta. Hal tersebut dapat diukur dari beberapa komponen indikator di bawah ini :

$\checkmark$ Penilaian aspek afektif petani terhadap program Gertak Tanpa Dusta.

$\checkmark$ Penilaian petani terhadap manfaat yang didapatkan dari program Gertak Tanpa Dusta.

$\checkmark \quad$ Penilaian petani terhadap kinerja petugas program Gertak Tanpa Dusta.

$\checkmark \quad$ Penilaian petani terhadap pelayanan petugas program Gertak Tanpa Dusta.

Komponen-komponen tersebut akan diinterpretasikan ke dalam bentuk pertanyaan sehingga akan mendapatkan penilaian skor dengan kategori "kurang baik" jika skor 4-20 dan "baik" jika skor $21-36$

3. Sikap : Suatu kemandirian yang terbentuk pada diri responden dalam berusahatani padi yang diukur dengan melihat derajat ketergantungannya terhadap keberadaan program Gertak Tanpa Dusta. Kemandirian semakin rendah pada ketergantungan yang tinggi. Ketergantungan diukur dari aspek kecenderungan responden untuk melepas atau tidak melepas bantuan yang diberikan dalam program. Berdasarkan 
Jurnal Media Agribisnis Vol. 2 No. 2 Tahun 2017 Hal 60 - 68

Media Komunikasi Hasil Penelitian Bidang Ilmu Agribisnis

ISSN print 2548-7027

ISSN online 2541-6898

skor dari kuisioner yang berkisar antara 6-54 maka sikap kemandirian dikategorikan sebagai berikut :

$\checkmark \quad$ Sikap kemandirian rendah $=$ skor ketergantungan tinggi : $31-54$

$\checkmark \quad$ Sikap kemandirian tinggi $=$ skor ketergantungan rendah : $6-30$

\section{Identitas Responden}

\section{HASIL DAN PEMBAHASAN}

Umur Responden. Soekartawi (1995), menyatakan bahwa semakin muda umur petani biasanya semakin semangat untuk lebih mengetahui yang belum mereka ketahui, sehingga mereka lebih cepat mengadopsi inovasi baru, walaupun terkadang mereka kurang berpengalaman. Tabel 3 terlihat bahwa selang kelas umur $48-53$ tahun memiliki frekuensi tertinggi (23,29\%), sedangkan frekuensi terendah terdapat pada selang 60 - 65 tahun dengan rata-rata umur 42 tahun.

Tabel 3. Distribusi Frekuensi Responden Bedasarkan Umur Tahun 2017

\begin{tabular}{lccc}
\hline No. & $\begin{array}{c}\text { Selang Kelas Umur } \\
\text { (Tahun) }\end{array}$ & $\begin{array}{c}\text { Frekuensi } \\
\text { (orang) }\end{array}$ & $\begin{array}{c}\text { Persentase } \\
(\%)\end{array}$ \\
\hline 1. & $24-29$ & 10 & 13.70 \\
2. & $30-35$ & 13 & 17.81 \\
3. & $36-41$ & 10 & 13.70 \\
4. & $42-47$ & 16 & 21.92 \\
5. & $48-53$ & 17 & 23.29 \\
6. & $54-59$ & 5 & 6.85 \\
7. & $60-65$ & 2 & 2.74 \\
& Jumlah & 73 & 100 \\
\hline
\end{tabular}

Sumber : Data Primer yang diolah, 2017

Pendidikan Responden. Pendidikan baik formal maupun nonformal sangat penting dalam memperoleh pengetahuan dan keterampilan yang menentukan pola berfikir seseorang. Tabel 4 menunjukkan petani berpendidikan mulai dari SD/Sederajat sampai dengan S1. Mayoritas tingkat pendidikan petani hanya SD/Sederajat, yaitu sebanyak 52 petani atau sebesar $71.23 \%$.

Tabel 4. Distribusi Frekuensi Responden Berdasarkan Tingkat Pendidikan Tahun 2017

\begin{tabular}{llcc}
\hline No. & \multicolumn{1}{c}{ Tingkat Pendidikan } & $\begin{array}{c}\text { Frekuensi } \\
\text { (orang) }\end{array}$ & $\begin{array}{c}\text { Persentase } \\
(\%)\end{array}$ \\
\hline 1. & SD/Sederajat & 52 & 71.23 \\
2. & SLTP/Sederajat & 15 & 20.55 \\
3. & SLTA/Sederajat & 5 & 6.85 \\
4. & S1 & 1 & 1.37 \\
\hline & Jumlah & 73 & 100 \\
\hline
\end{tabular}

Sumber : Data primer yang diolah, 2017

Jumlah Tanggungan Keluarga Responden. Jumlah tanggungan keluarga merupakan salah satu faktor yang mempengaruhi keberhasilan berusahatani, karena semakin banyak jumlahnya maka semakin banyak kebutuhan yang akan dipenuhi oleh kepala 
Jurnal Media Agribisnis Vol. 2 No. 2 Tahun 2017 Hal 60 - 68

Media Komunikasi Hasil Penelitian Bidang Ilmu Agribisnis

ISSN print 2548-7027

ISSN online 2541-6898

keluarga. Tanggungan keluarga terdiri dari istri, anak serta anggota keluarga lainnya yang tinggal bersama. Tabel 5 menunjukkan bahwa mayoritas petani memiliki tanggungan keluarga 4 orang yaitu sebanyak 34 petani (46.58\%), sedangkan yang memiliki tanggungan keluarga paling sedikit adalah 2 orang yaitu sebanyak 3 petani $(4.11 \%)$ dengan rata-rata jumlah tanggungan keluarga sebanyak 4 orang.

Tabel 5. Distribusi Frekuensi Responden Berdasarkan Jumlah Tanggungan Keluarga Tahun 2017

\begin{tabular}{lccc}
\hline No. & $\begin{array}{c}\text { Jumlah Tanggungan Keluarga } \\
\text { (Orang) }\end{array}$ & $\begin{array}{c}\text { Frekuensi } \\
\text { (orang) }\end{array}$ & $\begin{array}{c}\text { Persentase } \\
(\%)\end{array}$ \\
\hline 1. & 2 & 3 & 4.11 \\
2. & 3 & 20 & 27.40 \\
3. & 4 & 34 & 46.58 \\
4. & 5 & 12 & 16.44 \\
5. & 6 & 4 & 5.48 \\
\hline & Jumlah & 73 & 100 \\
\hline
\end{tabular}

Sumber : Data primer yang diolah, 2017

Penggunaan Lahan Responden. Luas lahan merupakan variabel yang berperan penting dalam produksi padi, semakin banyak jumlah luas lahan yang dimiliki oleh petani maka semakin besar peluang untuk memperoleh produksi yang relative lebih besar besar. Rata-rata petani memiliki luas lahan $2 \mathrm{Ha}$. Tabel 6, terlihat bahwa sebagian besar petani mempunyai luas lahan padi $0.5-1.1$ Ha yaitu sebanyak 29 petani (39.73\%) dengan rata-rata luas lahan seluas 2.1 Ha. Dilihat dari konsepnya, Moskowitz dan Orgel, 1969 dalam Walgito, (2003) menyatakan bahwa persepsi merupakan proses pengorganisasian penginterpretasian terhadap stimulus yang diterima oleh individu sehingga merupakan sesuatu yang berarti, dan merupakan aktivitas yang integrated dalam diri individu tersebut. Persepsi dalam penelitian ini diartikan sebagai pandangan petani terhadap program.

Tabel 6. Distribusi Frekuensi Responden Berdasarkan Penggunaan Lahan Tahun 2017

\begin{tabular}{lccc}
\hline No. & Luas Lahan (Ha) & Frekuensi (Petani) & Persentase (\%) \\
\hline 1. & $0.5-1.1$ & 29 & 39.73 \\
2. & $1.2-1.8$ & 9 & 12.33 \\
3. & $1.9-2.5$ & 11 & 15.07 \\
4. & $2.6-3.2$ & 9 & 12.33 \\
5. & $3.3-3.9$ & 2 & 2.74 \\
6. & $4.0-4.6$ & 12 & 16.44 \\
7. & $4.7-5.3$ & 1 & 1.37 \\
\hline & Jumlah & 73 & 100 \\
\hline
\end{tabular}

Sumber : Data Primer yang diolah, 2017 
Jurnal Media Agribisnis Vol. 2 No. 2 Tahun 2017 Hal 60 - 68

Media Komunikasi Hasil Penelitian Bidang Ilmu Agribisnis

ISSN print 2548-7027

ISSN online 2541-6898

\section{Gambaran Persepsi Masyarakat Tani terhadap Program Gertak Tanpa Dusta di Kabupaten Tanjabtim, Provinsi Jambi.}

Berdasarkan hasil analisis data menunjukkan sebagian besar dari petani $(80,8 \%)$ memiliki persepsi yang baik terhadap program, sedangkan yang memiliki persepsi yang kurang baik hanya 19,2\%. Adapun frekuensi petani berdasarkan persepsi terhadap program, dapat dilihat pada Tabel 7 yang memperlihatkan persentase petani pada tiap kategori, dimana sebagian besar petani memiliki persepsi yang baik terhadap program. Persepsi yang baik ini timbul karena gencarnya pelaksana program dalam menjalankan kegiatan ini dan banyaknya tawaran bantuan dalam program menyangkut faktor produksi berupa bibit, alat dan mesin yang sangat didambakan oleh petani dalam mewujudkan keberhasilan usahatani padinya.

Tabel 7. Distribusi Frekuensi Responden Berdasarkan Persepsi terhadap Program Gertak Tanpa Dusta tahun 2017

\begin{tabular}{lcc}
\hline \multicolumn{1}{c}{ Kategori Persepsi } & Frekuensi (KK) & Persentase (\%) \\
\hline Baik & 59 & 80,8 \\
Kurang baik & 14 & 19,2 \\
\multicolumn{1}{c}{ Jumlah } & 73 & 100 \\
\hline
\end{tabular}

Sumber : Data Primer yang diolah, 2017

Persepsi yang baik ini menggambarkan besarnya manfaat yang dirasakan oleh petani. Masyarakat tani terbuka untuk menerima ide dan gagasan baru berupa program dan kegiatan yang dilaksanakan di wilayahnya. Hanya saja masih terdapat sebagian petani yang masih memberikan penilaian kurang baik terhadap program. Tabel 7 terlihat sebanyak 14 petani (19.2\%) masih memiliki persepsi kurang baik. Petani pada golongan ini pada dasarnya dapat menerima program, hanya saja karena minimnya pengetahuan petani tersebut yang disebabkan karena kurangnya informasi dan komunikasi. Untuk mendapatkan informasi mereka hanya bertanya pada teman dekat atau tetangga yang berada disekitarnya, sehingga mereka hanya berpedoman pada apa yang disampaikan oleh tetangganya. Persepsi yang kurang baik ini perlu dicermati, karena dapat menghambat keberlangsungan program.

\section{Gambaran Sikap Kemandirian Petani di Kabupaten Tanjabtim, Provinsi Jambi}

Sikap dalam penelitian ini berkaitan dengan pendirian untuk mandiri dalam berusahatani padi sehingga tidak tergantung lagi pada bantuan pemerintah yang selama ini ditawarkan dalam program. Dengan demikian kemandirian seorang petani semakin tinggi dengan semakin rendahnya ketergantungan pada segala macam bentuk bantuan yang dicanangkan dalam program. Derajat ketergantungan responden terhadap bantuan dipakai sebagai indikator kemandiriannya. Dalam hal ini semakin tinggi skor ketergantungan responden mengindikasikan kemandirian yang rendah dan sebaliknya.

Tabel 8. Distribusi Frekuensi Responden Berdasarkan Sikap terhadap Kegiatan Program Gertak Tanpa Dusta

\begin{tabular}{ccc}
\hline Sikap Kemandirian & Frekuensi (KK) & Presentase (\%) \\
\hline Rendah & 46 & 63 \\
Tinggi & 27 & 37 \\
Jumlah & 73 & 100 \\
\hline
\end{tabular}

Sumber : Data Primer yang diolah, 2017 
Jurnal Media Agribisnis Vol. 2 No. 2 Tahun 2017 Hal 60 - 68

Media Komunikasi Hasil Penelitian Bidang Ilmu Agribisnis

ISSN print 2548-7027

ISSN online 2541-6898

Hasil analisis menunjukkan bahwa $63 \%$ petani memiliki sikap kemandirian dengan kategori rendah dan hanya $37 \%$ petani yang memiliki sikap kemandirian tinggi. Ini berarti $63 \%$ petani dalam usahatani padinya cenderung tergantung pada bantuan dari pemerintah sehingga mereka enggan berusahatani padi sendiri tanpa bantuan. Hal ini bisa dijadikan indikator bahwa kekuatan ekonomi petani masih rendah untuk menjalankan usahatani padinya sehingga berharap besar dari bantuan.

\section{Kaitan antara Persepsi terhadap Program Gertak Tanpa Dusta dengan Sikap Kemandirian Masyarakat Tani di Kabupaten Tanjabtim, Provinsi Jambi.}

Arindita,S (2003) berpendapat bahwa persepsi adalah suatu proses pemberian arti atau makna terhadap lingkungan. Dalam hal ini persepsi mencakup penafsiran obyek, penerimaan stimulus (Input), pengorganisasian stimulus, dan penafsiran terhadap stimulus yang telah diorganisasikan dengan cara mempengaruhi perilaku dan pembentukan sikap. Di lain pihak Holahan, C. J. 1978 menyatakan bahwa sikap dipengaruhi oleh persepi. Dalam hal ini seseorang yang memiliki persepsi yang baik terhadap kegiatan program ini akan menunjukkan sikap yang positif.

Berlandaskan teori tersebut maka persepsi masyarakat tani terhadap program yang baik menunjukkan rasa senang akan adanya bantuan dalam program sehingga menimbulkan ketergantungan yang besar. Ketergantungan inilah yang selanjutnya membentuk sikap kemandirian yang rendah, dan sebaliknya. Tabel 9 menujukkan bahwa mayoritas responden yang memiliki persepsi baik terhadap program mayoritas membentuk sikap kemandirian yang rendah dari 59 responden dengan persepsi baik terdapat 41 responden $(69,5 \%)$ dengan sikap kemandirian yang rendah. Sedangkan responden dengan persepsi kurang baik mayoritas menunjukkan 64,3\% memiliki sikap kemandirian yang tinggi yaitu 9 dari 14 orang yang memiliki persepsi kurang baik.

Tabel 9. Tabel Kontingensi Hasil Tabulasi

Variable yang diteliti Kategori Sikap Kemandirian

\begin{tabular}{lccc} 
& Tinggi & Rendah & Jumlah \\
\multicolumn{1}{c}{ Kategori Persepsi } & & & 59 \\
\hline Baik & 18 & 41 & 14 \\
Kurang baik & 9 & 5 & 73 \\
\hline Jumlah & 27 & 46 & \\
\hline
\end{tabular}

Sumber : Data Primer yang diolah, 2017

Catatan: $X^{2}$ tabel: $3,841\left(X^{2}\right.$ pada $\alpha=0,05$ dan $\left.\mathrm{Db} . \mathrm{k}-1\right)$

Hasil penelitian menunjukkan bahwa antara persepsi masyarakat tani terhadap program dengan sikap kemandirian dalam berusahatani padinya menunjukkan kaitan yang nyata. Hal ini ditunjukkan dengan $X^{2}$ hitung $(4,19)$ yang lebih besar dari $X^{2}$ tabel $(3,841)$. Fenomena ini memberikan petunjuk bahwa persepsi yang baik terhadap program, menggambarkan besarnya harapan petani terhadap segala bantuan yang diberikan dalam program sehingga terbentuk keengganan untuk berusahatani secara mandiri bila bantuan itu terhenti. Petani mendukung dan menginginkan sistem bantuan ini dilanjutkan karena dirasakan sangat meringankan beban dalam berusahatani. Hal ini memberikan sinyal bahwa pemerintah belum bisa melepas petani untuk bergerak sendiri, tetapi harus lebih 
Jurnal Media Agribisnis Vol. 2 No. 2 Tahun 2017 Hal 60 - 68

Media Komunikasi Hasil Penelitian Bidang Ilmu Agribisnis

ISSN print 2548-7027

ISSN online 2541-6898

memilih untuk melanjutkan pelaksanaan program ini dengan sistem insentif berupa berbagai bantuan.

\section{KESIMPULAN}

Sebagian besar dari petani peserta program Gertak Tanpa Dusta menunjukkan $80,8 \%$ memiliki persepsi yang baik terhadap program tersebut. Tetapi masih terdapat sebagian petani yang memberikan penilaian kurang baik terhadap program ini yaitu sebanyak 14 petani (19.2\%). Sikap kemandirian dalam berusahatani padi menunjukkan mayoritas petani $(63 \%)$ memiliki sikap kemandirian dengan kategori rendah dan hanya $37 \%$ petani yang memiliki sikap kemandirian tinggi. Responden yang memiliki persepsi baik terhadap program mayoritas membentuk sikap kemandirian yang rendah. Dalam hal ini dari 59 responden dengan persepsi baik terdapat 41 responden $(69,5 \%)$ memiliki sikap kemandirian yang rendah. Sedangkan responden dengan persepsi kurang baik mayoritas menujukkan sikap kemandirian tinggi yaitu 64,3\%. Persepsi petani peserta program terhadap program Gertak Tanpa Dusta memiliki kaitan yang nyata dengan sikap kemandirian dalam berusahatani padinya di Kabupaten Tanjabtim Provinsi Jambi.

\section{DAFTAR PUSTAKA}

Arindita, S. 2003. Hubungan antara Persepsi Kualitas Pelayanan dan Citra Bank dengan Loyalitas Nasabah. Skripsi (tidak diterbitkan). Fakultas Psikologi UMS. Surakarta.

BPS Provinsi Jambi. 2017.Pertumbuhan Ekonomi Provinsi Jambi Tahun 2016. Berita $\begin{array}{lllll}\text { Resmi Statistik } & \text { No.010/02/15/Th.XI, } & 6 & \text { Februari } 2017\end{array}$ http://jambi.bps.go.id/website/brs_ind/brsInd-20170217151211.pdf. Diakses 18 Februari 2017.

BPS Kabupaten Tanjabtim. 2016. Kabupaten Tanjung Jabung Timur Dalam Angka. https://tanjabtimkab.bps.go.id/webbeta/website/pdf_publikasi/KabupatenTanjung Jabung-Timur-Dalam-Angka-2016.pdf. Diakses 18 Februari 2017.

Holahan, Charles J. 1978. Envirionment and behavior. Plenum Press. New York.

Nasir, Moh. 1985. Metode Peneitian. Ghalia Indonesia. Jakarta.

Singarimbun, M., dan Sofian E. 1998. Metode Penelitian Survai. LP3ES. Jakarta. Soekartawi. 1995. Analisis Usahatani. Universitas Indonesia Press. Jakarta.

Sugiyono. 2004. Statistic Non Parametris. Alfa Beta. Bandung.

Walgito, Bimo. 2003.Psikologi Sosial(Suatu Pengantar). Penerbit Andi. Yogyakarta.

Winarno. S. 1994. Pengantar Penelitian Ilmiah (dalam metode tehnik).Penerbit Kanisius. Bandung. 